\title{
Structure Development and Control of Injection-Molded Hydroxylapatite-Reinforced Starch/EVOH Composites
}

\author{
R. L. REIS,,$^{1,2,3}$ A. M. CUNHA, ${ }^{3}$ P. S. ALLAN, ${ }^{4}$ M. J. BEVIS ${ }^{4}$ \\ ${ }^{1}$ Department of Metallurgical Engineering, Faculty of Engineering, University of Porto, Rua dos \\ Bragas, 4099 Porto Codex, Portugal \\ ${ }^{2} I N E B$, Institute for Biomedical Engineering, Porto, Portugal \\ ${ }^{3}$ Department of Polymer Engineering, University of Minho, Guimarães, Portugal \\ ${ }^{4}$ The Wolfson Centre for Materials Processing, Brunel University, Uxbridge, Middlesex UK
}

\begin{abstract}
This article reports on the development of novel composites of starch-based polymers reinforced with hydroxylapatite (HA). Two different grades of blends of starch and ethylene vinyl alcohol copolymers were reinforced with up to $30 \%(\mathrm{wt})$ of sintered and nonsintered HA. The initial compounding stage was carried out either in a rotating drum or by twin-screw extrusion (TSE). Compounds were injection molded using both conventional molding and a shear-controlled orientation in injection molding (Scorim) technique. It was possible to obtain composites with very good mechanical properties, approaching those of cortical bone. The best results were achieved for $30 \%$ sintered HA composites processed by TSE and Scorim, due to the in situ formation of HA fibers, and the development of molecular orientation and more compact microstructures in the moldings. This was confirmed by SEM analysis of the fracture surfaces, x-ray diffraction, and Raman spectroscopy. The biodegradability of the composites was also assessed and was found to be faster than that of the matrix. (c) 1997 John Wiley \& Sons, Inc. Adv Polym Techn 16: 263-277, 1997
\end{abstract}




\section{Introduction}

B iodegradable polymers are finding increasing uses in biomedical applications. ${ }^{1-5}$ Their utilization may include devices such as surgical sutures, several types of nonpermanent implants, ${ }^{3-5}$ and drug carriers in several specific drug delivery systems. ${ }^{1}$ The development of new polymers may be quite useful, especially in temporary applications for repair and regeneration of healing tissues. ${ }^{4,5}$

Starch-based polymers are known to be biodegradable $^{6-10}$ materials that may constitute an alternative to the currently used bioresorbable biomaterials. These polymers exhibit a range of properties that make them suitable for use as biomaterials..$^{10,11}$ Although the materials mechanical properties may be substantially improved by using nonconventional processing techniques, such as Scorim, ${ }^{11}$ their bulk mechanical performance is still inadequate even for small load bearing applications.

The development of degradable materials that possess adequate mechanical properties may lead to a new range of small load bearing applications for these systems. The combination of polymers with bioactive ceramics is expected to minimize the mismatch of mechanical properties of bioceramics and natural tissue. Several polymer matrix and bioactive ceramic reinforcements have been used to develop composites intended to emulate bone properties. ${ }^{12-17}$ Both bioinert ${ }^{12,17}$ and biodegradable polymers ${ }^{13-16}$ have been used as matrices, aiming at both permanent and temporary applications. In the latter case, there is still no reinforced system exhibiting adequate mechanical performance, satisfactory bone-bonding properties, and controlled degradation behavior. This work reports the development of novel thermoplastic composites based on hydroxylapatite-reinforced starch blends. Nonconventional composite processing routes, such as Scorim, ${ }^{11,18-20}$ are used to attain the required mechanical performance.

\section{Materials and Methods}

In this work, starch-based polymers were reinforced with different amounts of hydroxylapatite (HA) powders. Hydroxylapatite, $\mathrm{Ca}_{5}\left(\mathrm{PO}_{4}\right)_{3}(\mathrm{OH})$, is a ceramic that belongs to the $\mathrm{P}_{3} / \mathrm{m}$ crystallo- graphic group. HA is the major inorganic constituent of human bones and, due to its chemical affinity to bone and osteoinductive properties it can induce, to a particular implant, a bone-bonding behavior. Also, its mechanical properties, which are typical of a ceramic, may be useful for reinforcing a certain polymer.

In this research, two different grades of blends of starch and ethylene vinyl alcohol copolymer (obtained from Novamont, Italy) were used as matrix material: SEVA-B (trade name Mater-Bi AIO5H) and SEVA-C (Mater-Bi 1128RR). These grades differ mainly in their rheological behavior, ${ }^{10,21}$ presenting, respectively, the following melt flow index (MFI) values (at $170^{\circ} \mathrm{C}, 49 \mathrm{~N}$ ): 2.64 and $0.71 \mathrm{~g} / 600 \mathrm{~s}$.

Following previous work in which the properties of these grades were disclosed, ${ }^{10,11}$ this article reports the development of HA-reinforced SEVA matrix composites. Both sintered (at $1200^{\circ} \mathrm{C}$ for 12 hours) and nonsintered HA (Tahei Chemical, Japan) were used as reinforcement. The nonsintered HA powder was formed by aggregates of primary particles with an average diameter of about $0.2-0.3 \mu \mathrm{m}$, as determined by laser granulometry using methyl alcohol as solvent. The corresponding specific surface area assessed by BET (with $\mathrm{N}_{2}$ ) was $33-37 \mathrm{~m}^{2} / \mathrm{g}$. After sintering and crushing in a ball mill the average diameter of the HA particles was in the $3-7-\mu \mathrm{m}$ (media of $4.5 \mu \mathrm{m}$ ) range, with the specific surface area being 1-2 $\mathrm{m}^{2} / \mathrm{g}$. In both cases, $\mathrm{x}$-ray diffraction analysis showed that the material was very pure and only residual amounts of other phases could be detected.

The experimental plan included the preparation of compounds with $10 \%, 20 \%$, and $30 \%$ (wt) HA. Two different compounding routes were investigated: (i) simple mixing in a rotating drum, and (ii) corotating twin-screw extrusion (TSE) followed by mechanical palletizing. This compounding operation was done with a barrel temperature profile between $90^{\circ}$ and $170^{\circ} \mathrm{C}$, in a Betol BTS40L corotating twin-screw extruder.

These compounds were used to produce circular cross-section tensile samples with two different diameters (1.5 and $5 \mathrm{~mm}$, which will be designated as $\phi 1.5$ and $\phi 5$, respectively). The $\phi 1.5$ samples were molded with a conventional injection machine (Klockner-Ferromatik Desma FM20). The $\phi 5$ samples were injection molded with a Demag D-150 NCIII-K machine fitted with a Scorim (shearcontrolled orientation in injection molding) head. This equipment was used to produce both conventional 
INJECTION-MOLDED STARCH/EVOH COMPOSITES

TABLE I

Processing Conditions for Conventional Injection Molding

\begin{tabular}{lccccc}
\hline \multicolumn{1}{c}{ Material } & $\begin{array}{c}T_{\text {inj }} \\
\left({ }^{\circ} \mathrm{C}\right)\end{array}$ & $\begin{array}{c}T_{\text {mold }} \\
\left({ }^{\circ} \mathrm{C}\right)\end{array}$ & $\begin{array}{c}\text { Flow rate } \\
{\left[\mathrm{cm}^{3} / \mathrm{s}\right]}\end{array}$ & $\begin{array}{c}P_{\text {hold }} \\
{[\mathrm{MPa}]}\end{array}$ & $\begin{array}{c}\text { Cycle time } \\
{[\mathrm{s}]}\end{array}$ \\
\hline SEVA-B & 180 & 60 & 120 & 50 & 35 \\
SEVA-C & 185 & 60 & 120 & 50 & 35 \\
SEVA-B + HA & 185 & 60 & 130 & 55 & 40 \\
SEVA-C + HA & 190 & 60 & 130 & 55 & 40 \\
\hline
\end{tabular}

${ }^{a}$ For all compounds produced.

and Scorim $\phi 5$ moldings. The processing conditions used with both injection molding technologies are presented in Tables I and II.

Scorim technology is based on the action of two oscillating pistons that induce high shear fields in the melt during the holding/solidification stage. ${ }^{18-20}$ The result is a highly oriented microstructure with enhanced mechanical properties being possible for several materials, including SEVA-C, ${ }^{11}$ to increase both stiffness and ductility. ${ }^{11,20}$ Further details on Scorim technology may be found elsewhere. ${ }^{18,19}$

For the polymer matrix, two Scorim conditions, as reported in Table II, were selected from the initial processing trials. They differ on the maximum pressure applied during the compaction stage of the shearing cycle. Scorim condition S4, used for processing of the composites, was adjusted from S2 settings by increasing the injection temperature $\left(T_{\text {inj }}\right)$ and the Scorim time $\left(t_{\text {scoRIM }}\right)$. It was noted from the traces of the cavity pressure that the filled material was sheared by approximately five piston movements before the section solidified. The unfilled material, however, could be sheared by approximately seven piston movements before solidification was complete.
The molded samples were tensile tested to determine the ultimate tensile strength (UTS), the secant modulus at $1 \%$ strain $\left(E_{1 \%}\right)$, strain at break $\left(\epsilon_{r}\right)$, and the energy to break $\left(U_{b}\right)$. Due to the need for comparing the mechanical behavior of ductile materials (the matrix) with highly reinforced composites, UTS was selected instead of yield strength or fracture stress. The tensile tests were performed on an Instron 4505 universal mechanical testing machine, fitted with a resistive extensometer (gauge length $10 \mathrm{~mm})$, in a controlled environment $\left(23^{\circ} \mathrm{C}\right.$ and $55 \%$ $\mathrm{RH})$. The cross-head speed was $5 \mathrm{~mm} / \mathrm{min}(8.3 \times$ $10^{-5} \mathrm{~m} / \mathrm{s}$ ) until $1 \%$ strain, and then increased to $50 \mathrm{~mm} / \mathrm{min}$ until fracture $\left(8.3 \times 10^{-4} \mathrm{~m} / \mathrm{s}\right)$. The molded samples were stored under controlled temperature and moisture conditions until testing, and at least 10 samples of each condition were tested for determining the mechanical properties.

Materials degradation was assessed after several prefixed aging periods in a simulated physiological solution (HBSS [Hank's balanced salt solution], Gibco 041-04025M, from Life Technologies, Paisley, UK) at $37^{\circ} \mathrm{C}$. After being removed from the solution, one batch of samples was dried in an oven for $48 \mathrm{~h}$ at $70^{\circ} \mathrm{C}$ to determine the respective weight loss. The other batch of samples was stored in a room

TABLE II

Processing Conditions for SCORIM Equipment ${ }^{\mathrm{a}}$

\begin{tabular}{lcccccc}
\hline Condition & $\begin{array}{c}T_{\text {inj }} \\
\left({ }^{\circ} \mathrm{C}\right)\end{array}$ & $\begin{array}{c}T_{\text {mold }} \\
\left({ }^{\circ} \mathrm{C}\right)\end{array}$ & $\begin{array}{c}\text { Flow rate } \\
{\left[\mathrm{cm}^{3} / \mathrm{s}\right]}\end{array}$ & $\begin{array}{c}P_{\text {hold }} \\
{[\mathrm{MPa}]}\end{array}$ & $\begin{array}{c}t_{\text {scookim }} \\
{[\mathrm{s}]}\end{array}$ & $\begin{array}{c}P_{\max } \\
{[\mathrm{MPa}]}\end{array}$ \\
\hline Conventional & 170 & 60 & 160 & 50 & - & 150 \\
S2 & 170 & 60 & 180 & 13 & 40 & 211 \\
S3 & 170 & 60 & 180 & 13 & 40 & 290 \\
S4 & 190 & 60 & 200 & 13 & 48 & 210 \\
\hline
\end{tabular}

a All with the Scorim pistons oscillating out of phase. 
with controlled atmosphere $\left(23^{\circ} \mathrm{C}, 55 \% \mathrm{RH}\right)$ for 2 weeks to stabilize the moisture content. Then the samples were tensile tested to evaluate the changes in mechanical properties as a function of the degradation time.

Complementary materials characterization also included scanning electron microscopy (SEM) analysis of the fracture surfaces, energy dispersive spectroscopy (EDS), Fourier transform infrared spectroscopy (FTIR), Raman spectroscopy, and x-ray diffraction (XRD).

\section{Results and Discussion}

The results of the tensile tests are summarized in Tables III and IV. The data presented correspond to a minimum of 10 samples for each condition. Examples of typical stress-vs.-strain curves are presented in Figures 1 and 2. The differences between the unreinforced compounds of SEVA-B and SEVA-C (curves $a$ and $b$ in Fig. 1) are associated with the respective molecular weight. As expected, SEVA-C exhibits higher strength and stiffness. However, the ductility is similar for both materials.

The stiffness of these two blends is favored by the addition of bioactive bone-like ceramics. This effect is enhanced for the case of sintered HA-reinforced composites due to the much higher modulus of this filler. The tensile strength has a different dependence, being slightly increased for the SEVA-B polymer and adversely affected for SEVA-C, especially for low reinforcement amounts. As could be anticipated, the ductility and energy absorption of both polymers are severely decreased with the HA additions. Nevertheless, the respective figures are much higher than the typical values for bulk sintered HA, and are of the order of magnitude of other reinforced biodegradable systems.

The mechanical performance of SEVA-C material, namely stiffness and strength, was improved through the utilization of the Scorim processing technique, as shown in Table IV and Figure 2. Depending on the selected processing conditions it was possible to increase simultaneously the strength, the stiffness, and the ductility (Scorim S2) or to increase further $E_{1 \%}$ and UTS with a decrease of the ductility - both $\epsilon_{r}$ and $U_{b}$ (Scorim S3). This general improvement of properties is the result of the highly oriented molecular structure induced by the oscillating shear field imposed on the solidifying polymer melt.

It is important to note that the Scorim results are based on $\phi 5-\mathrm{mm}$ samples and conventional injection molding on $\phi 1.5-\mathrm{mm}$ ones. The modulus for SEVA-C material in the thinner samples (1.93 GPa) is higher than that obtained for the Scorim equipment without applying the shearing cycle $(1.81 \mathrm{GPa}$, referred to as "SEVA-C - conventional" in Table IV). These results strongly reinforce the high sensitivity of the mechanical performance of these polymers to molecular orientation imposed through processing. In fact, this can be confirmed from Raman and XRD spectra in Figures $3 a$ and $b$ and 4. Both the relative intensity increment and the decrease of the full-width half media is a strong indication of the enhanced molecular orientation of the $\phi 1.5$ samples relative to the raw-material granules.

TABLE III Tensile Test Results of Conventional Injection Molding Samples ( $\phi 1.5 \mathrm{~mm})$

\begin{tabular}{lcrrr}
\hline \multicolumn{1}{c}{ Material } & $\begin{array}{c}\text { UTS } \\
(\mathrm{MPa})\end{array}$ & $E_{1 \%}(\mathrm{GPa})$ & $\epsilon_{r}(\%)$ & $U_{b}\left(\mathrm{~kJ} / \mathrm{m}^{2}\right)$ \\
\hline SEVA-B & $25.1 \pm 0.9$ & $1.21 \pm 0.18$ & $79.9 \pm 14.5$ & $165.9 \pm 30.6$ \\
SEVA-B + 20\% HA n/s & $25.7 \pm 1.5$ & $1.58 \pm 0.39$ & $5.2 \pm 1.4$ & $7.9 \pm 2.3$ \\
SEVA-B + 20\% HA s & $27.5 \pm 1.8$ & $2.06 \pm 0.35$ & $3.2 \pm 1.3$ & $5.1 \pm 1.7$ \\
SEVA-C & $37.2 \pm 1.5$ & $1.93 \pm 0.21$ & $64.4 \pm 11.8$ & $160.4 \pm 33.4$ \\
SEVA-C + 10\% HA S & $29.4 \pm 1.9$ & $2.14 \pm 0.86$ & $4.2 \pm 0.8$ & $7.9 \pm 4.5$ \\
SEVA-C + 20\% HA n/s & $33.2 \pm 3.0$ & $1.98 \pm 0.94$ & $5.9 \pm 2.0$ & $11.3 \pm 4.5$ \\
SEVA-C + 20\% HA S & $35.8 \pm 4.5$ & $2.56 \pm 0.41$ & $3.5 \pm 1.1$ & $7.4 \pm 3.4$ \\
SEVA-C + 20\% HA S-TSE & $41.1 \pm 1.9$ & $4.51 \pm 0.78$ & $2.3 \pm 0.2$ & $5.7 \pm 1.1$ \\
SEVA-C + 30\% HA s-TSE & $43.9 \pm 5.0$ & $5.10 \pm 0.59$ & $1.5 \pm 0.3$ & $4.5 \pm 0.6$ \\
\hline
\end{tabular}

Data presented corresponds to a minimum of 10 samples. s—sintered; n/s—nonsintered; TSE-twin-screw extruded. 
TABLE IV

Tensile Test Results of SCORIM Injection Molding Samples ( $\phi 5 \mathrm{~mm}$ )

\begin{tabular}{lccrr}
\hline \multicolumn{1}{c}{ Material } & $\begin{array}{c}\text { UTS } \\
(\mathrm{MPa})\end{array}$ & $E_{1 \%}(\mathrm{GPa})$ & $\epsilon_{r}(\%)$ & $U_{b}\left(\mathrm{~kJ} / \mathrm{m}^{2}\right)$ \\
\hline SEVA-C-conventional & $35.6 \pm 3.2$ & $1.81 \pm 0.16$ & $22.4 \pm 5.8$ & $52.5 \pm 12.7$ \\
SEVA-C-S2 & $38.9 \pm 3.1$ & $2.02 \pm 0.31$ & $35.9 \pm 6.1$ & $116.7 \pm 22.4$ \\
SEVA-C-S3 & $41.8 \pm 0.8$ & $2.97 \pm 0.23$ & $7.1 \pm 2.0$ & $15.8 \pm 5.2$ \\
SEVA-C + 20\% HA S-TSE-S4 & $29.3 \pm 0.5$ & $5.64 \pm 0.41$ & $13.2 \pm 2.2$ & $10.2 \pm 0.2$
\end{tabular}

Data presented corresponds to a minimum of 10 samples. s-sintered; TSE_twin-screw extruded.

Figures 5 and 6 show SEM micrographs of fracture surfaces for conventional and Scorim S1 $\phi 5$ samples, respectively. The conventional sample exhibits a more brittle pattern and a clear fracture nucleation point (Fig. 5b), which is typical of conventional molded SEVA grades. ${ }^{10,11}$ This result is reproducible and all samples show this feature. The Scorim shearing of the melt leads to a much more compact structure, consistently observed for all samples and Scorim conditions, which eliminates these internal defects (Fig. 6b). The presence of a more compact structure in Scorim moldings was identified before, ${ }^{11,19}$ being confirmed in the present study both by density and water sorption data. The density of the Scorim molded samples is 3\% (for S2) to $8 \%$ (for S3) higher for the Scorim samples, and these samples tend to uptake less water $-5 \%$ less (for S2) and 11\% less (for S3) after 30-day immersion in Hank's balanced salt solution. Although substantial shearing was imposed to the melt during Scorim molding, according to FTIR studies ${ }^{10}$ no noticeable degradation was induced in the polymer matrix.

The addition of HA to SEVA allowed, simultaneously, for the improvement of mechanical per-

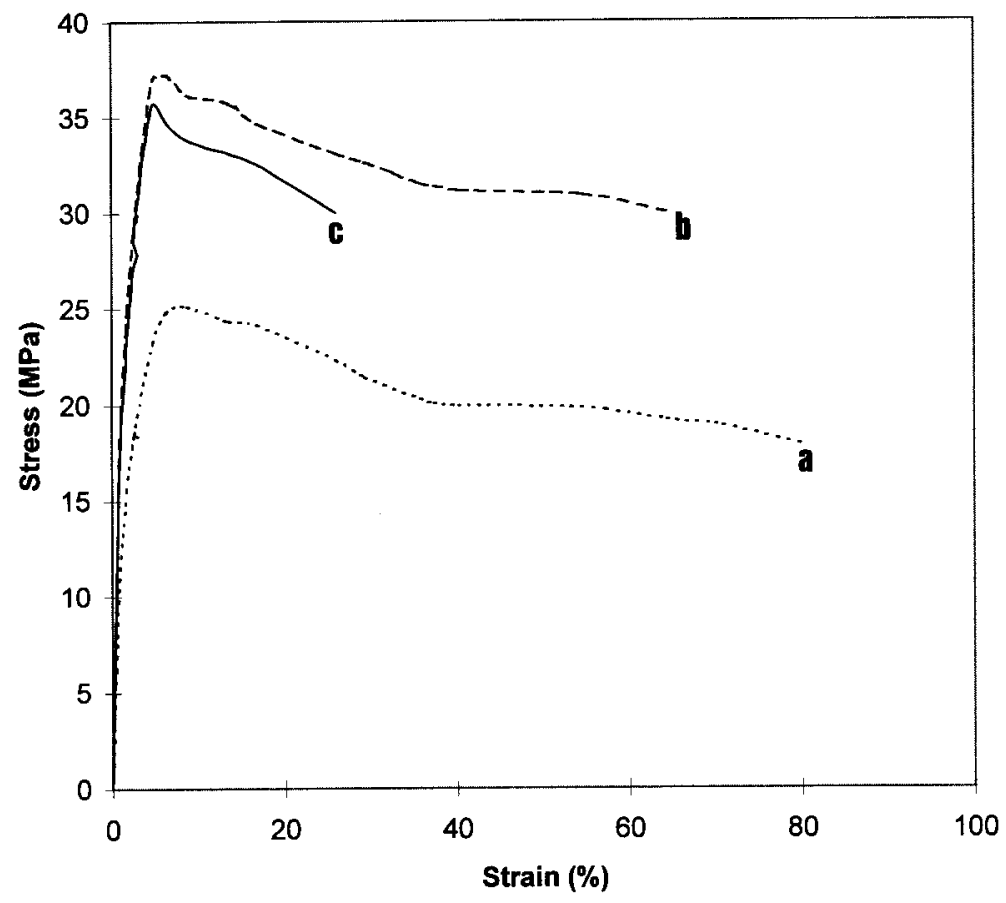

FIGURE 1. Typical stress vs. strain curves for conventionally molded: (a) SEVA-B $\phi 1.5 \mathrm{~mm}$; (b) SEVA-C $\phi 1.5 \mathrm{~mm}$; (c) SEVA-C $\phi 5 \mathrm{~mm}$. 


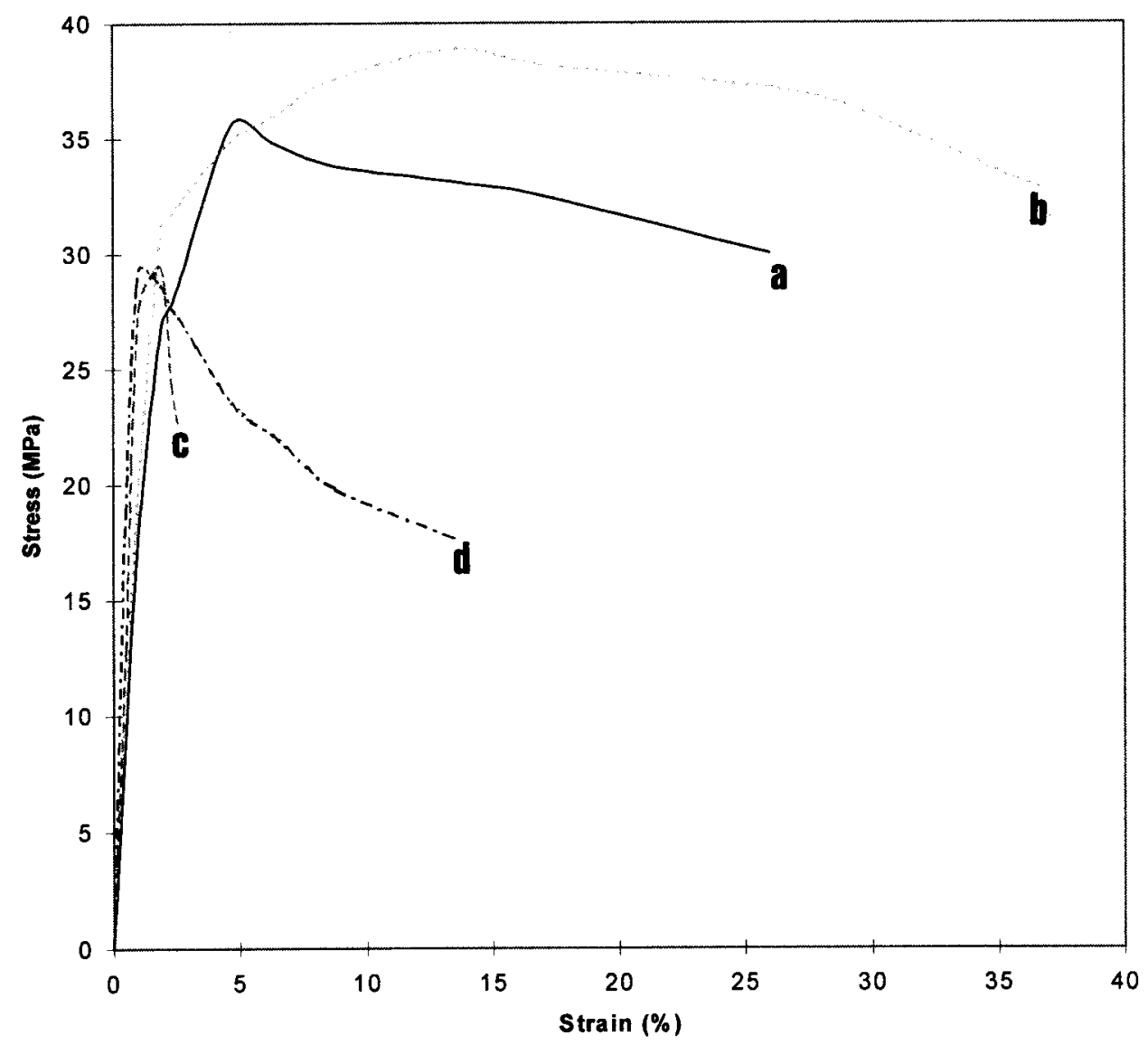

FIGURE 2. Typical stress vs. strain curves for: (a) SEVA-C conventional molding ( $\phi 1.5 \mathrm{~mm})$; (b) SEVA-C Scorim processed ( $\phi 5 \mathrm{~mm}$ ); (c) SEVA-C $+20 \%$ HA s conventional molding $(\phi 1.5 \mathrm{~mm})$; (d) SEVA-C $+20 \%$ HA s Scorim processed $(\phi 5 \mathrm{~mm})$.

formance and enhancement of polymer degradability. For conventional injection molding (Table III), by adding $20 \%$ of sintered HA to SEVA-C it was possible to attain a modulus of $2.56 \mathrm{GPa}$ $\left(\varepsilon_{r}=3.5 \%\right)$ compared to the original $1.93 \mathrm{GPa}$ $\left(\varepsilon_{r}=64.4 \%\right)$ of the matrix. These results are in the range of the mechanical properties of cancellous bone. ${ }^{12}$

When the molding compounds were prepared by TSE, the $E_{1 \%}$ was increased to $4.51 \mathrm{GPa}\left(\boldsymbol{\varepsilon}_{r}=2.3 \%\right)$ for $20 \%$ sintered $\mathrm{HA}$, and to $5.10 \mathrm{GPa}\left(\boldsymbol{\varepsilon}_{r}=1.5 \%\right)$ for $30 \%$ sintered HA. SEM micrographs of the respective fracture surfaces are shown in Figures 7 and 8 . In the rotational drum compounded samples the HA particles did not agglomerate and were detached from the embedding matrix, which underwent most of the deformation, leading to formation of the polymer fibrils observed in Figure $7 \mathrm{~b}$.

In the TSE compounded samples (Fig. 8) the small HA particles (which were almost spherical with an average size of $4.5 \mu \mathrm{m}$ ) were agglomerated to form small fibers (sizes up to $100 \times 40 \mu \mathrm{m}$ ) oriented in the mold filling direction (the same as the mechanical testing solicitation). The formation of ceramic fibers oriented in the testing direction and presenting an aspect ratio of around 4 had a beneficial effect on the mechanical performance attained. These fibers formed in situ were well dispersed in the polymer matrix and assured a larger load transfer interface, which was responsible for the better mechanical properties obtained.

When Scorim technology was used to process SEVA / HA composites it was possible to improve the modulus up to $5.64 \mathrm{GPa}$ with an unusually high ductility $\left(\varepsilon_{r}=13.2 \%\right)$. These results are consistent with Figures 9 and 10. The fibers were well dispersed and strongly bonded to the matrix providing for an efficient load transfer between the polymer 


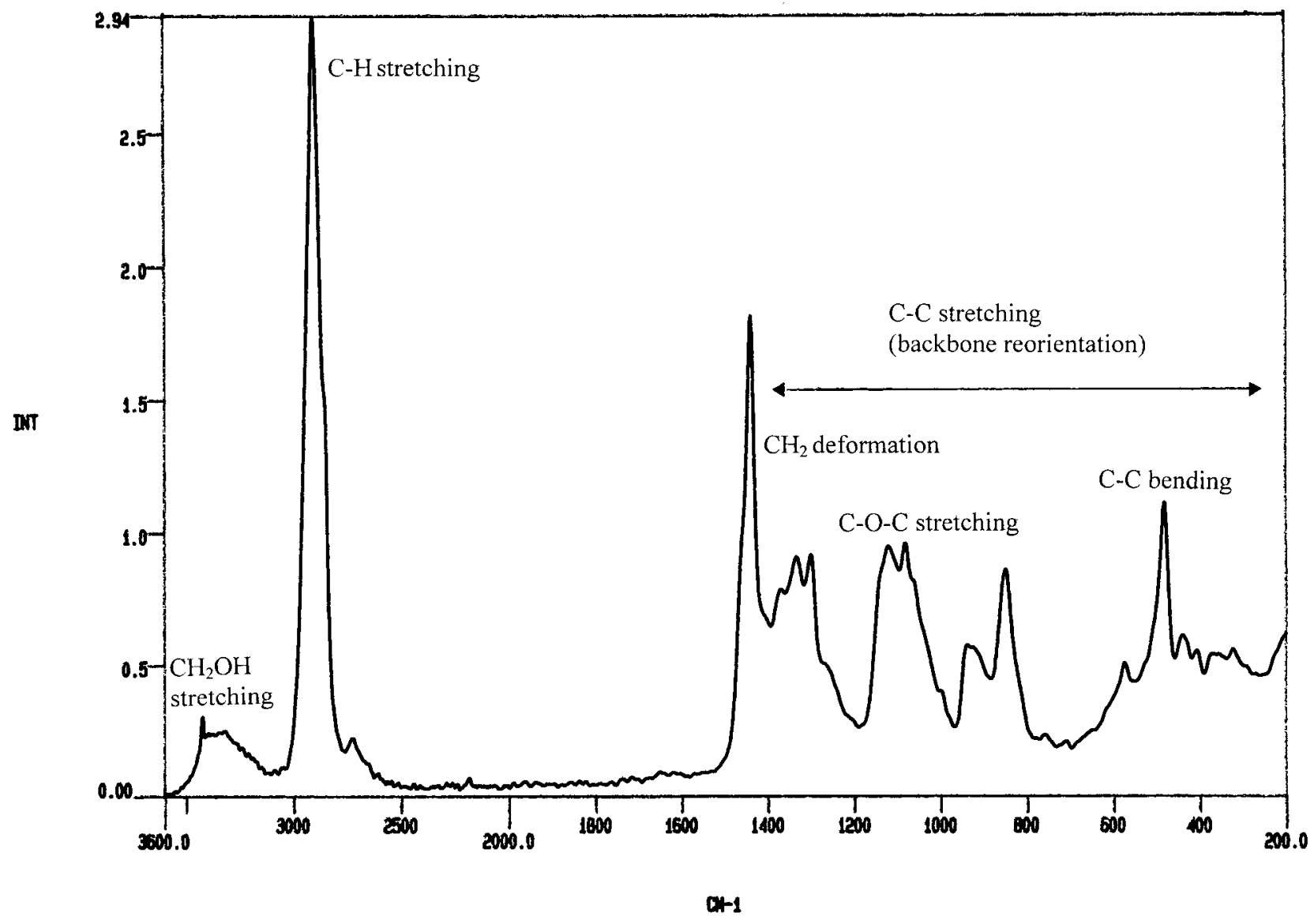

(a)

FIGURE 3. Raman spectra for: (a) SEVA-C granules.

and reinforcement, confirming what has been noted previously.

The observation of XRD spectra in Figure $4 \mathrm{~b}$ confirms that HA was not degraded by the processing route used. In fact, all relevant HA peaks are present, and all others may be attributed to the polymer matrix. These spectra are also useful for comparing the level of molecular orientation induced in the $\phi 1.5-\mathrm{mm}$ conventionally molded composites and in the $\phi 5-\mathrm{mm}$ Scorim processed samples. The assumption that the geometry of the conventional moldings leads to a slightly higher degree of orientation than the application of Scorim to thicker samples is validated by these spectra. Of course this result can be particularly helpful for research purposes, but has no application when considering the development of thick implants such as bone plates. For that purpose the use of Scorim is a unique way of inducing anisotropy on very thick sections as reported before. ${ }^{11,18-20}$ Nevertheless, these findings could lead to the development of starch-based fibers or even surgical sutures exhibiting very good mechanical properties.

These encouraging results indicate that by increasing the added HA concentration and using a processing route based on TSE it should be possible to achieve modulus matching (with that of cortical bone-7-21 GPa) with simultaneous enhancement of sample ductility.

A fundamental study dealing with the degradation mechanisms and their relationships with the observed weight loss and variations on the $E_{1 \%}$, UTS, and $\boldsymbol{\varepsilon}_{r}$ as a function of the aging time, of the SEVA-based materials, has been published previously. ${ }^{22}$ In this study, only the influence of HA will be briefly described. The presented mechanical properties changes are based on $E_{1 \%}$, the parameter of higher relevance for the proposed application.

The degradation behavior of the several developed materials is plotted in Figure 11a and b, re- 


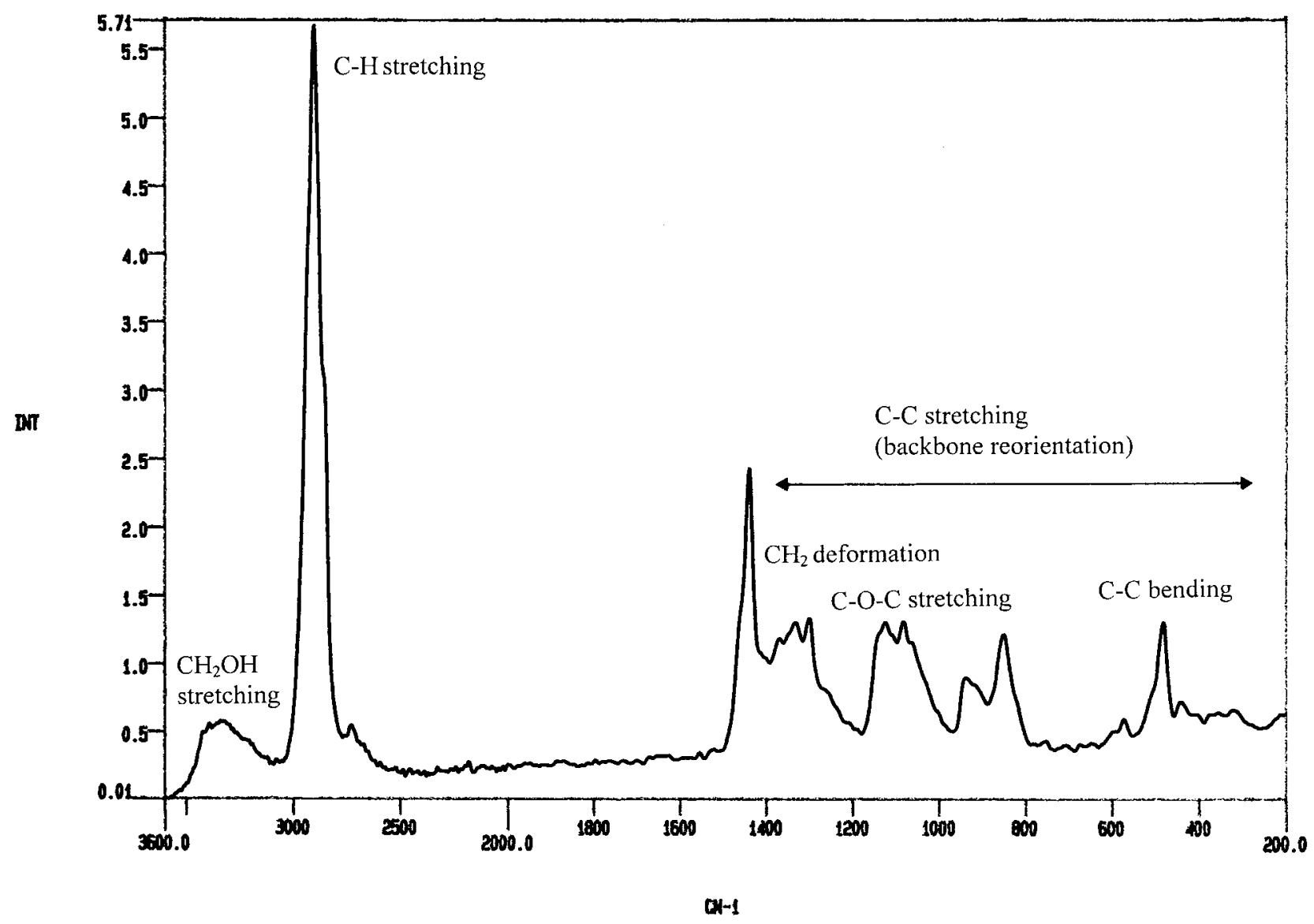

(b)

FIGURE 3. (continued) (b) SEVA-C $\phi 1.5-\mathrm{mm}$ conventional molding; The main vibrations detected are labeled. Note differences in the relative intensity scales.

spectively, in terms of dry weight loss and modulus reductions, both versus the degradation time in HBSS at $37^{\circ} \mathrm{C}$. The weight loss depends strongly on the HA additions, on the type of HA (sintered or nonsintered), and on the number of processing stages (thermomechanical cycles imposed on the materials). In all cases, HA reinforcement tends to increase the degradation rate, because both the matrix and the reinforcement are degrading simultaneously. Nonsintered HA reinforced samples seem to lose weight faster, which may be due to the much smaller size of the HA agglomerates, which tends to create more interfaces and to facilitate the solution attack. The increase in the number of processing steps also has an influence, leading to higher degradation rates. This could be related to the high sensitivity of these polymers to thermal degradation. When TSE is applied before injection molding, no meaningful changes are observed, but the route TSE plus Scorim tends, clearly, to increase the degradation rates as a consequence of the production of a small quantity of low-molecular-weight components that leach to the solution.

In terms of modulus changes (reported in Fig. 11b) all materials exhibit a behavior similar to the matrix polymer. Materials are degraded faster in the first aging days and then tend to stabilize their $E_{1 \%}$ values. However, the relative ranking of original mechanical properties is respected. The incorporation of HA drastically changes the morphology of fracture surfaces of degraded samples as may be observed in Figure 12a-c. It seems that the HA-reinforced materials are much harder to attack than the original SEVA matrix materials. Nevertheless, there is preferential attack at the SEVA/HA interface (Fig. 12c) that is responsible for the deterioration of properties. It is believed that both the incorporation of more HA and the surface treatment of the HA 


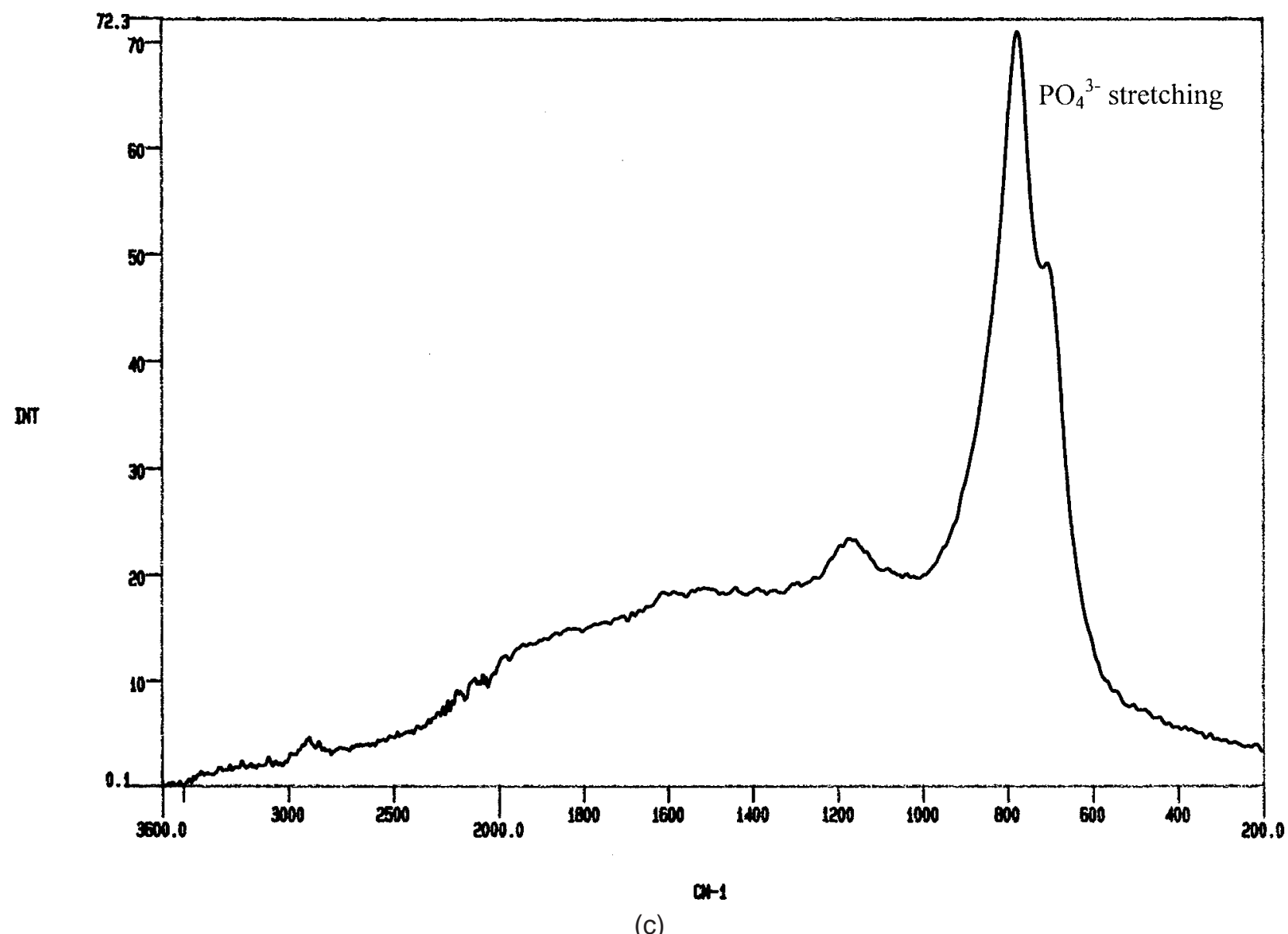

FIGURE 3. (continued) (c) SEVA-C $+20 \%$ HA s $\phi 1.5-\mathrm{mm}$ conventional molding.

particles to improve SEVA/HA adhesion may solve this problem, and allow for the development of composites with tissue-tailored mechanical and degradation behaviors.

\section{Conclusions}

The main conclusions of this work are:

1. HA-reinforced SEVA matrix composites exhibit a range of properties that may be very useful in temporary tissue replacement applications.

2. It was possible to improve the properties of the composites dramatically through the development of special processing routes. The best results were attained for 30\% (wt) sintered HAreinforced composites processed by TSE and
Scorim, due to the in situ formation of HA fibers and to the molecular orientation and more compact structures obtained.
$E_{1 \%}$

$\boldsymbol{\varepsilon}_{r}$

MFI

$P_{\text {hold }}$

$P_{\max }$

$T_{\text {inj }}$

$T_{\text {mold }}$

$t_{\text {SCORIM }}$

$U_{b}$

UTS

\section{Nomenclature}

secant modulus at $1 \%$ strain (GPa)

strain at break $(\%)$

melt flow index (g/600s)

holding pressure $(\mathrm{MPa})$

maximum cavity pressure monitored

during the Scorim cycle (MPa)

injection temperature $\left({ }^{\circ} \mathrm{C}\right)$

mold temperature $\left({ }^{\circ} \mathrm{C}\right)$

Scorim cycle time (s)

energy to break point $\left(\mathrm{kJ} / \mathrm{m}^{2}\right)$

ultimate tensile strength $(\mathrm{MPa})$ 


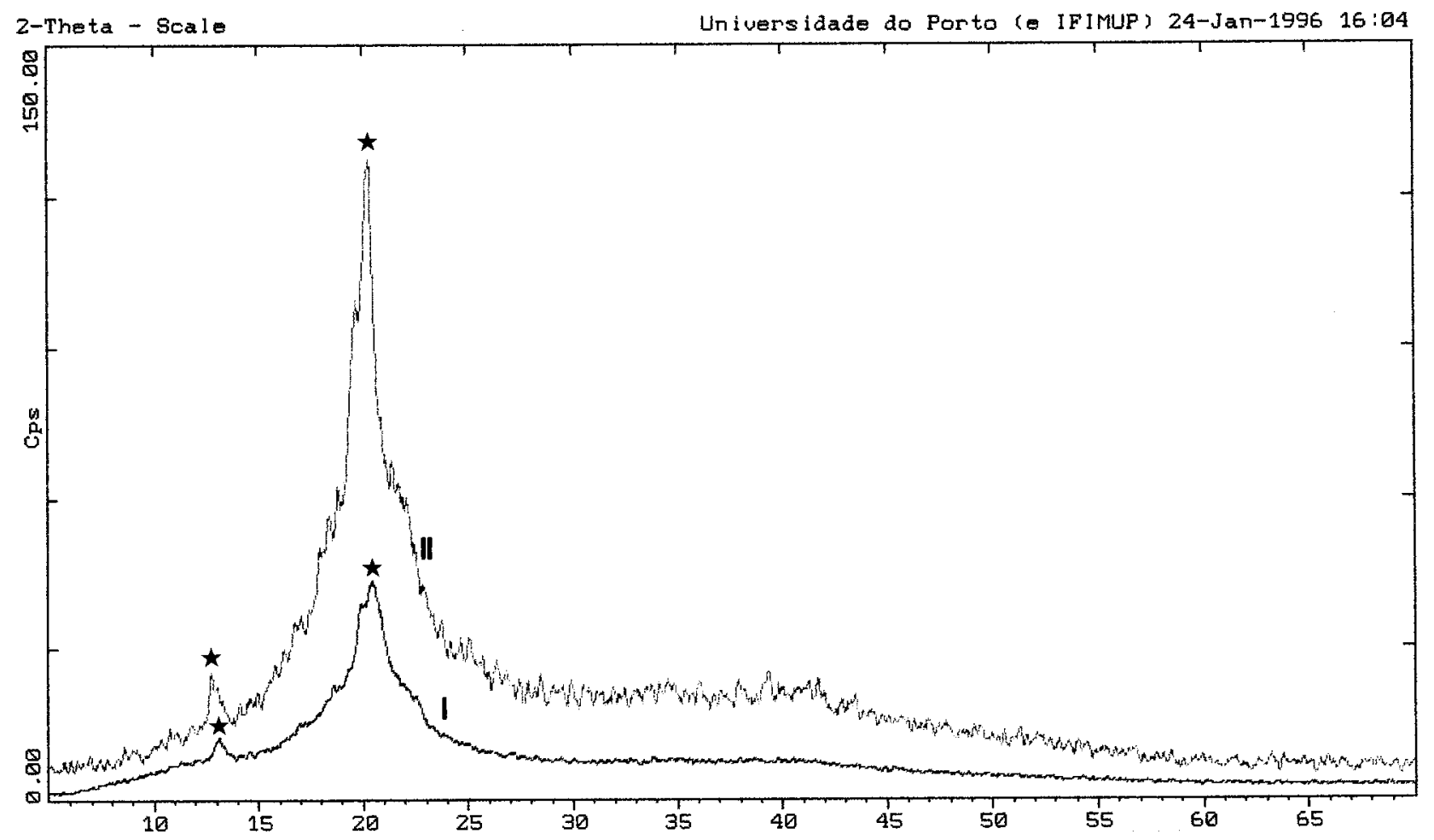

(a)

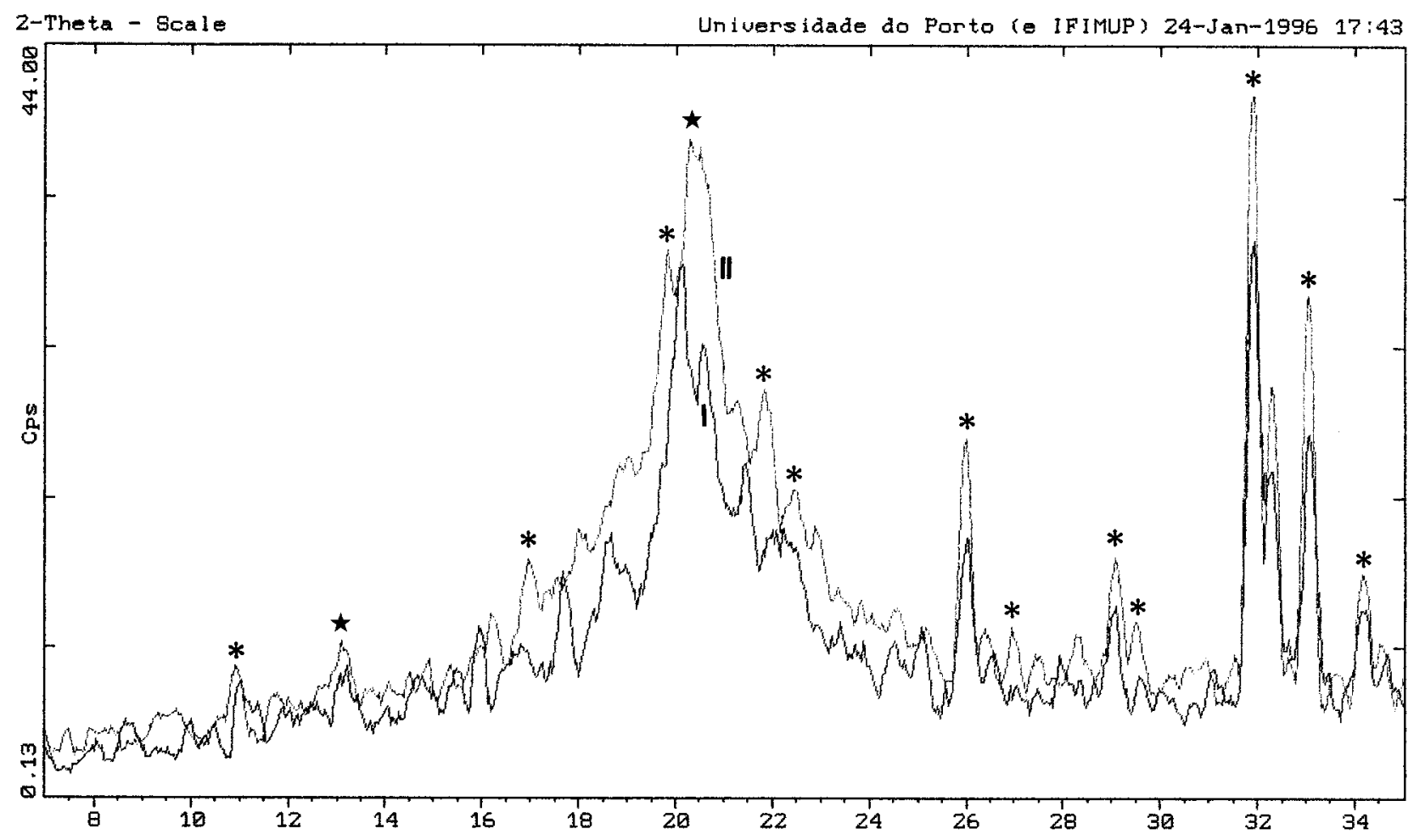

(b)

FIGURE 4. XRD spectra of (a) I-SEVA-C raw material granules, II-SEVA-C $\phi 1.5$-mm conventional molding; and (b) I-SEVA-C + 20\% HA s-TSE Scorim S2 moldings, II-SEVA-C + 20\% HA s-TSE conventional moldings. For all spectra: $\star$-identifies SEVA; $*$-HA characteristics peaks. 

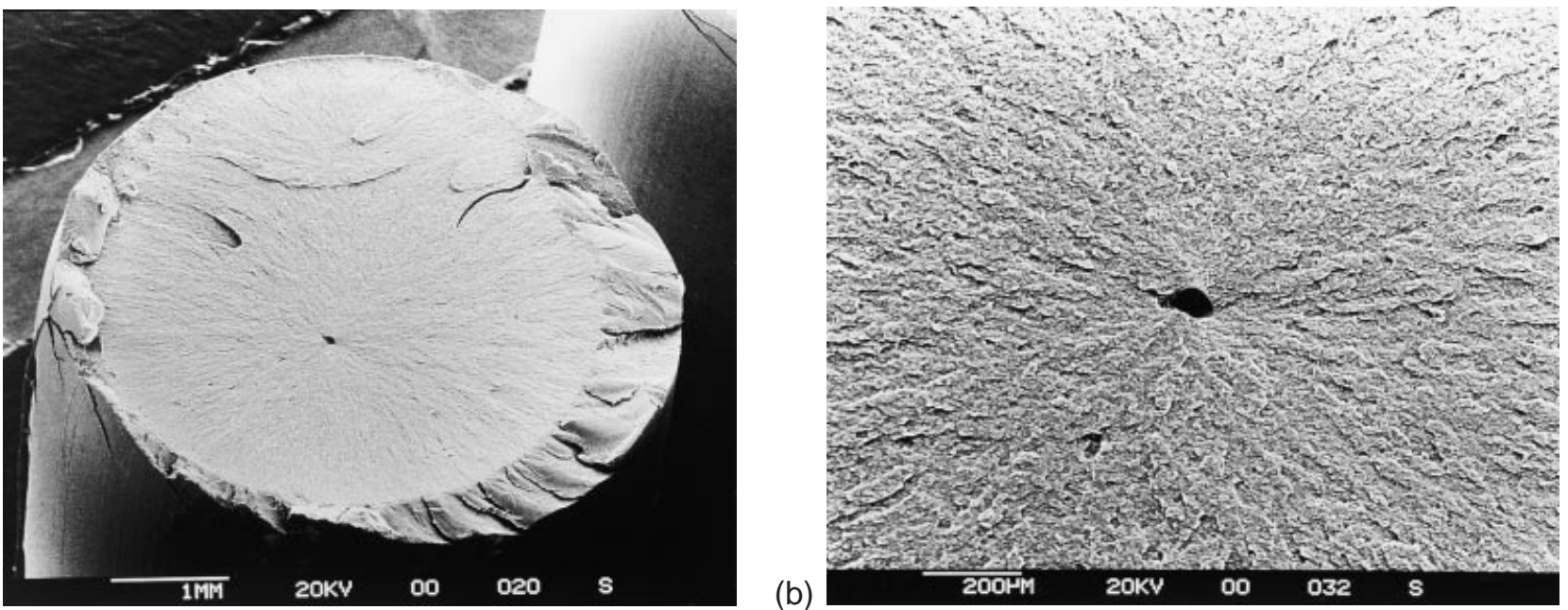

FIGURE 5. (a) SEM micrograph of the tensile fracture surface of a $\phi 5 \mathrm{~mm}$ conventional molding. (b) Magnification of the fracture surface showing a clear nucleation point.

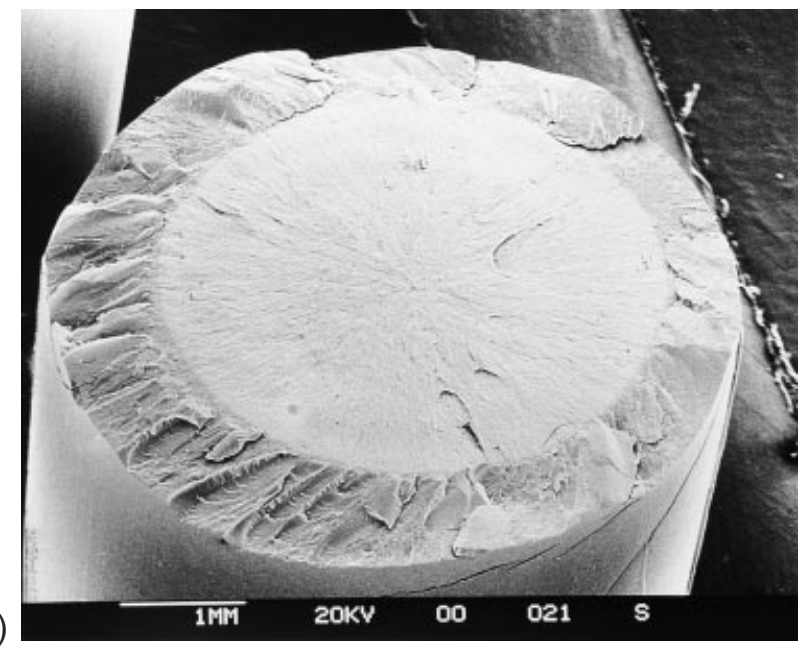

(b)

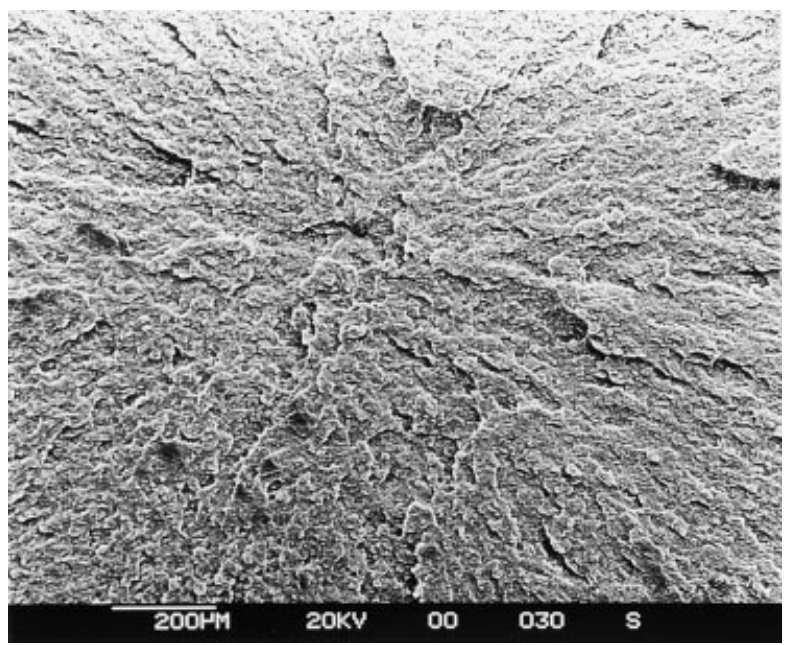

FIGURE 6. (a) SEM micrograph of the tensile fracture surface of a $\phi 5 \mathrm{~mm}$ Scorim S1 molding. (b) Magnification of the fracture surface on which no nucleation point may be distinguished.
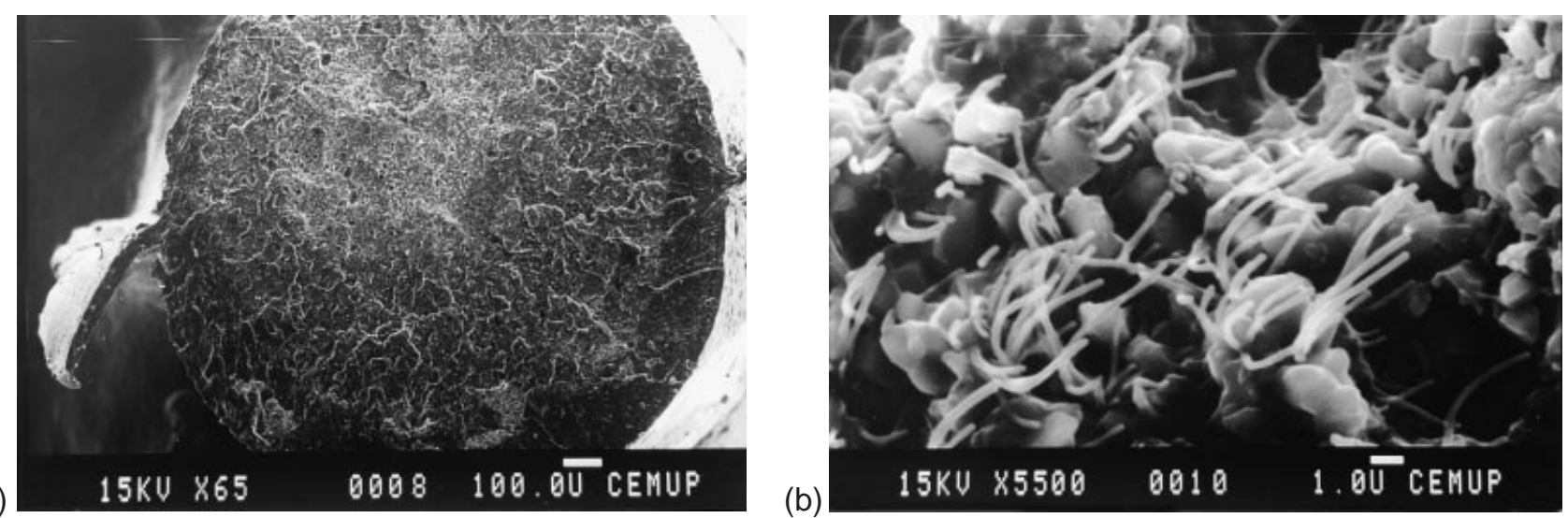

FIGURE 7. (a) SEM micrograph of the tensile fracture surface of a conventionally molded $20 \%$ sintered $\mathrm{HA}$ composite. (b) High magnification of the polymer fibrils formed around the HA particles. 
(a)

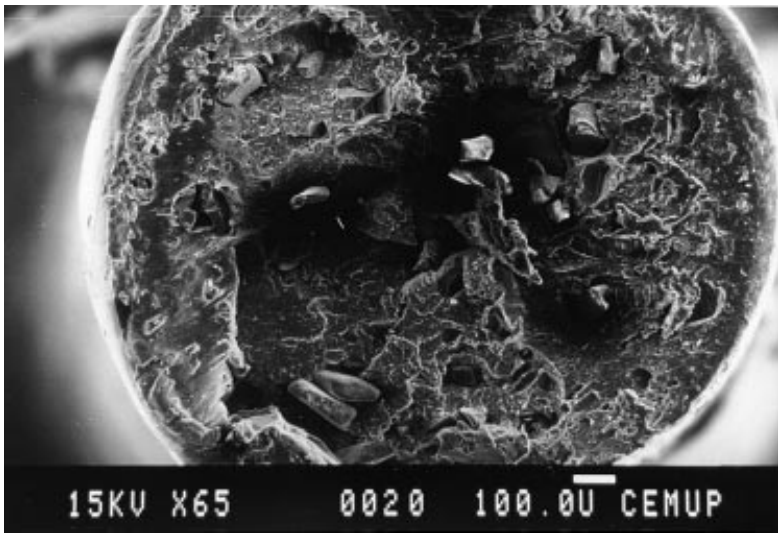

(b)

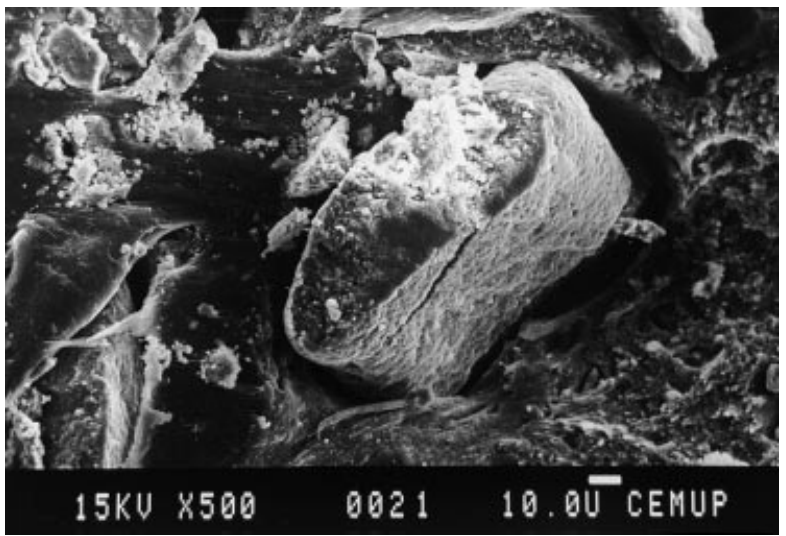

FIGURE 8. (a) SEM micrograph of a tensile fracture surface of a conventionally molded $20 \%$ sintered HA composite. Twin-screw extrusion was used for producing compounds for the injection molding. It may be seen that HA fibers with an aspect ratio of approximately 4 as that magnified on (b) were formed in situ and are oriented in the mechanical solicitation direction.

(a)

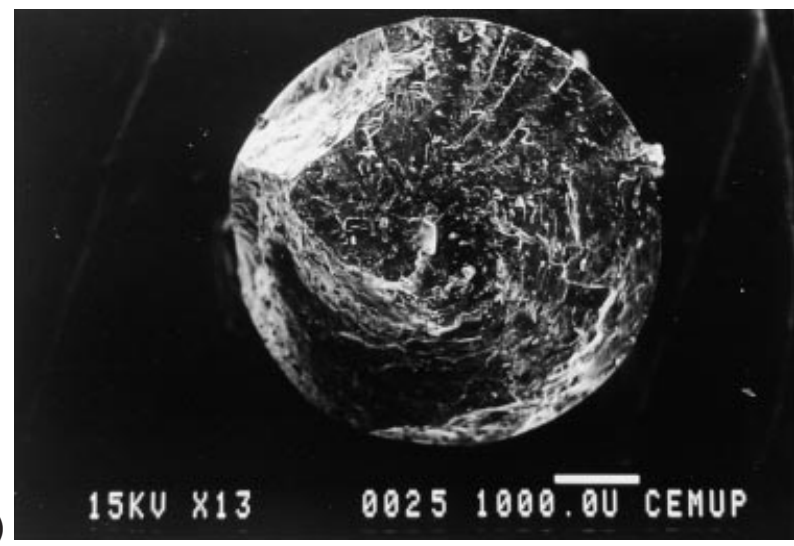

(b)

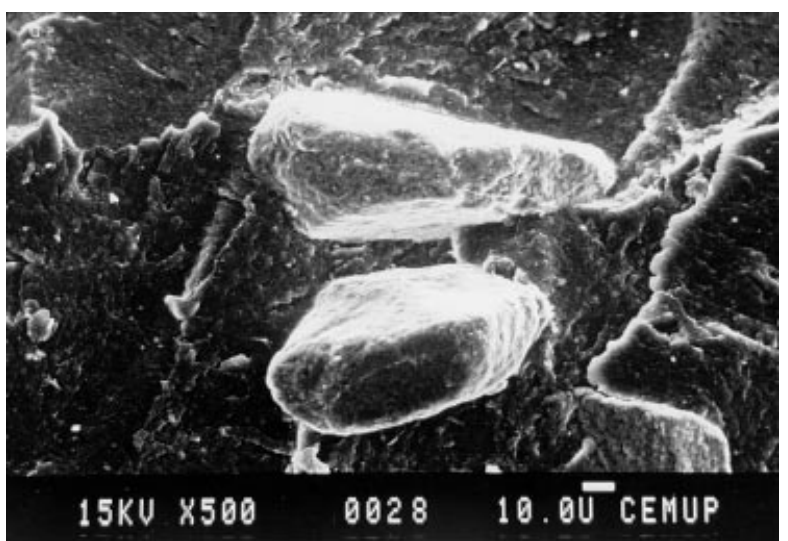

FIGURE 9. (a) SEM micrograph of a tensile fracture surface of a Scorim injection molded $20 \%$ sintered HA composite. Twin-screw extrusion was used for compounding SEVA with HA prior to injection molding. Unusually high ductility can be observed. (b) A similar agglomeration of HA particles leading to the formation of fibers was detected, but the structure is clearly much more compact.

(a)

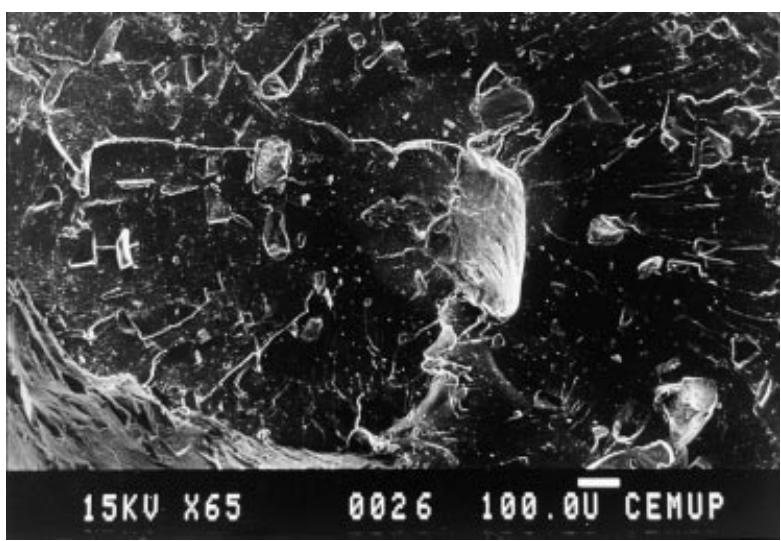

(b)

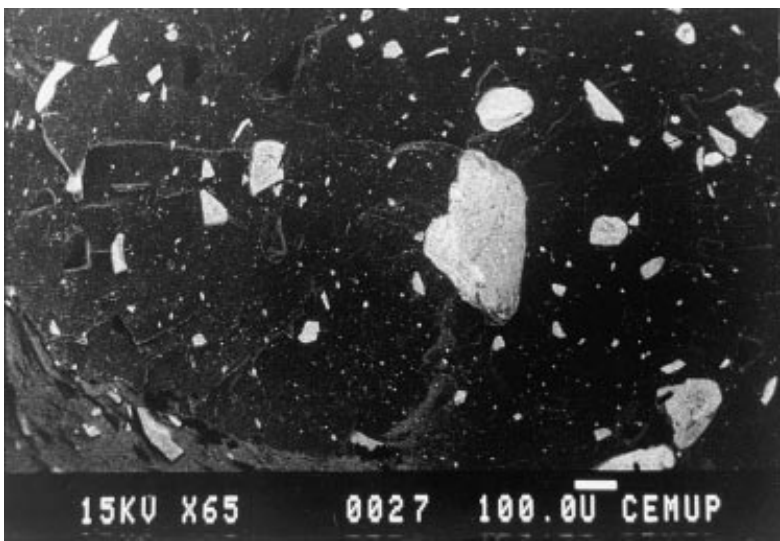

FIGURE 10. (a) SEM aspect of the fracture nucleation point of SEVA-C $+20 \%$ HA s-TSE S4 composites (center of the sample in Fig. 9a). (b) Backscattering electron image making clearer the distribution of HA particles agglomerates. 
INJECTION-MOLDED STARCH/EVOH COMPOSITES

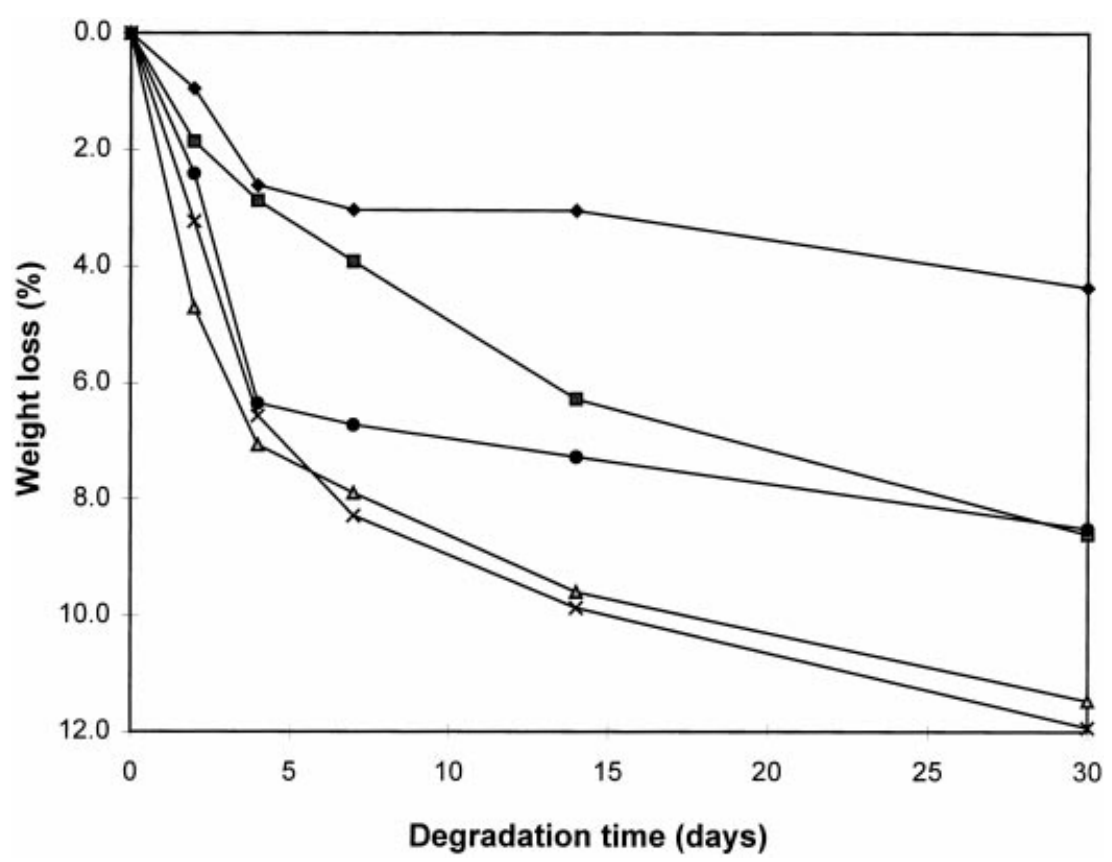

(a)

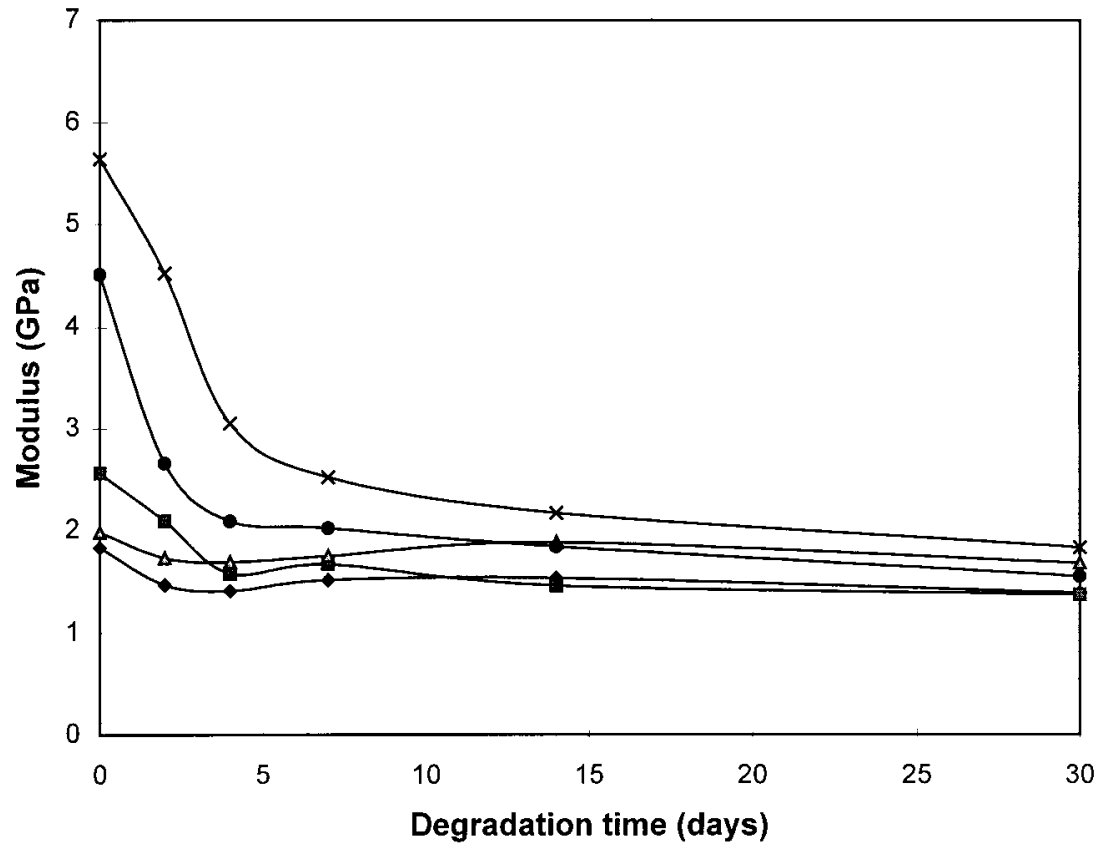

(b)

FIGURE 11. (a) Dry weight loss vs. degradation time and (b) modulus loss vs. degradation time for: $(\bullet)$ SEVA-C; $(\triangle)$ SEVA-C + 20\% HA n/s; (口) SEVA-C + 20\% HA s; (•) SEVA-C + 20\% HA s-TSE; (*) SEVA-C + 20\% HA s-TSE + Scorim. 
(a)

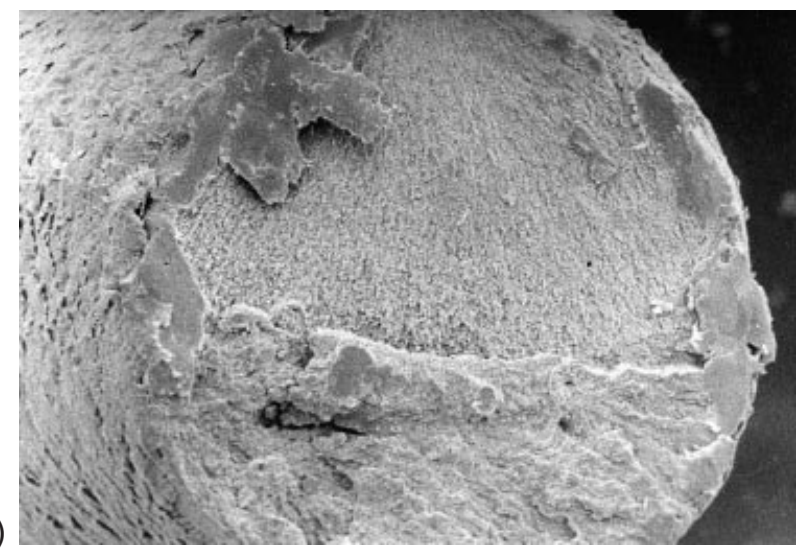

(c)

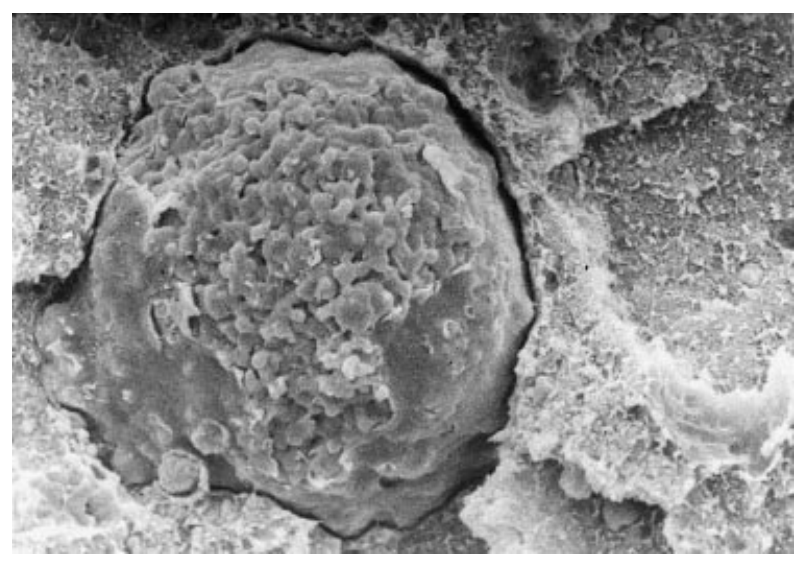

\section{Acknowledgments}

Rui L. Reis acknowledges the PRAXIS XXI Programme for a research grant supporting his work in the UK. We are grateful to Novamont, Italy, and Tahei Chemicals, Japan, for offering the materials used in this research. We also thank Mrs. Cristina Ribeiro and Cacilda Moura for helping in the Raman studies, and Prof. Bessa Meneses, Dr. Vitor Amaral, and Bernardo Almeida for support in the XRD experiments.

\section{References}

1. T. Hayashi, Prog. Polym. Sci., 19, 663 (1994).

2. P. U. Rokkanen, Ann. Med., 23, 109 (1991).

3. J. C. Knowles and G. W. Hastings, J. Mater. Sci. Mater. Med., 3, 352 (1992). (b)

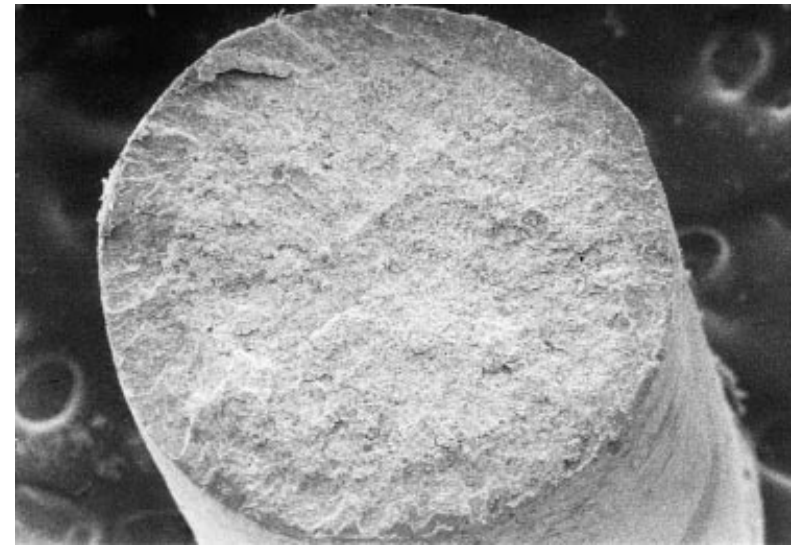

FIGURE 12. SEM micrographs of tensile fracture surfaces of conventionally molded $\phi 1.5-\mathrm{mm}$ samples degraded in Hank's balanced salt solution at $37^{\circ} \mathrm{C}$ for 14 days: (a) SEVA-C; SEVA-C $+20 \%$ HA s; (c) magnification of (b) showing the preferential attack on the interface around the HA particles.
4. K. P. Adriano, T. Pohjonen, and P. Tormalla, J. Appl. Biomater., 5, 133 (1994).

5. A. U. Daniels, K. P. Andriano, W. P. Smutz, M. K. O. Chang, and J. Heller, J. Appl. Biomater., 5, 51 (1994).

6. C. Bastioli, V. Bellotti, L. Del Guidice, and G. Gilli, J. Environ. Polym. Degrad., 1, 181 (1993).

7. G. J. L. Griffin, Polym. Degrad. Stabil., 45, 241 (1994).

8. R. F. T. Stepto and I. Tomka, Chimia, 41, 76 (1987).

9. M. Bhattarcharya, U. R. Vaidya, D. Zhang, and R. Narayan, J. Appl. Polym. Sci., 57, 539 (1995).

10. R. L. Reis and A. M. Cunha, J. Mater. Sci. Mater. Med., 6, 786 (1995).

11. R. L. Reis, A. M. Cunha, P. S. Allan, and M. J. Bevis, J. Polym. Adv. Technol., 7, 784 (1996).

12. M. Wang, W. Bonfield, and L. L. Hench, in Bioceramics 8, J. Wilson and L. L. Hench (Eds). Butterworth-Heinemann, New York, 1995, p. 383.

13. C. C. P. M. Verheyen, J. R. Wijn, C. A. van Blitterswijk, and K. de Groot, J. Biomed. Mater. Res., 26, 1277 (1992).

14. C. C. P. M. Verheyen, C. P. A. T. Klein, J. M. A. de BlieckHogervorst, J. G. C. Wolke, C. A. van Blitterswijk, and K. de Groot, J. Mater. Sci. Mater. Med., 4, 58 (1993).

15. S. Higashi, T. Yamamuro, T. Nakamura, Y. Ikada, S. H. Hyon, and K. Jamshidi, Biomaterials, 7, 183 (1986). 
INJECTION-MOLDED STARCH/EVOH COMPOSITES

16. J. C. Knowles and G. W. Hastings, J. Mater. Sci. Mater. Med., 4, 102 (1993).

17. R. L. Oréfice, G. P. La Torre, J. K. West, L. L. Hench, in Bioceramics 8, J. Wilson, and L. L. Hench (Eds)., ButterworthHeinemann, New York, 1995, p. 409.

18. P. S. Allan and M. J. Bevis, British Patent 2170-140-B (1987).
19. P. S. Allan and M. J. Bevis, Plast. Rubber Proc. Appl., 7, 3 (1987).

20. P. S. Allan and M. J. Bevis, Comp. Manuf., 2, 79 (1990).

21. C. Bastioli, V. Bellotti, and A. Rallis, Rheol. Acta, 33, 307 (1994).

22. R. L. Reis, S. C. Mendes, A. M. Cunha, and M. J. Bevis, Polym. Int, 43, 347 (1997). 